\title{
DESARROLLO ECONÓMICO DE JAPÓN: DE LA GÉNESIS AL LLAMADO MILAGRO ECONÓMICO*
}

\author{
FRANCISCO CORREA RESTREPO"* \\ SMC UNIVERSITY (SUIZA)
}

Recibido/ Received/ Recebido: 19/01/2016-Aceptado/ Accepted / Aprovado: 30/06/2016

\begin{abstract}
Resumen
El objetivo de este artículo es establecer el origen y la evolución del desarrollo económico de Japón en el siglo veinte, en particular en la época del llamado milagro económico japonés. Para tal fin se hace una descripción histórica de las reformas educativas, políticas y económicas establecidas desde la era Edo hasta la década de 1970, así como de las diferentes coyunturas económicas y políticas que recayeron sobre Japón durante en el período 1945-1970 XX. Se concluye que para entender el desarrollo económico de Japón es necesario analizar los cambios sociales, políticos y económicos acaecidos en el país durante el siglo XIX y, en particular, el papel del Estado y los grupos empresariales en la inserción de la economía japonesa en los mercados internacionales.

Palabras clave: Desarrollo económico; Política industrial; Planeación; Reformas; Crecimiento económico.
\end{abstract}

\section{JAPAN'S ECONOMIC DEVELOPMENT:FROM THE GENESIS TO THE SO CALLED ECONOMIC MIRACLE}

\begin{abstract}
The aim of this paper is to establish the origin and evolution of the economic development of Japan in the twentieth century, particularly in the era of the so-called Japanese economic miracle. For this purpose a historical illustration of educational, economic and political reforms established from the Edo era to the 1970s is made, as well as different economic and political situations that happened in Japan during the period 1945-1970 XX. It is concluded that to understand the economic development of Japan is necessary to analyze the social, political and economic changes that have occurred in the country during the nineteenth century and, in particular, the role of government and business groups in the insertion of the Japanese economy in the international markets.

Keywords: Economic development; Industrial policy; Planning; Reforms; Economic growth.
\end{abstract}

\footnotetext{
Artículo de reflexión, realizado durante el curso de Historia Económica del PhD en Economía del SMC University (Suiza).

Economista y Especialista en Evaluación socioeconómica de proyectos de la Universidad de Antioquia, Magister en Ciencias Económicas de la Universidad Nacional de Colombia, Estudiante del PhD en Economía del SMC University (Suiza). Profesor asociado del programa de Economía y coordinador del Grupo de Investigación en Economía Aplicada (GEA) de la Universidad de Medellín. Dirección Postal: Universidad de Medellín, Carrera 87 no 30-65, Medellín, Antioquia (Colombia). Teléfono: (57) (4) -340555, Ext. 5618. Correo electrónico: fcorrea@udem.edu.co
} 


\title{
DESENVOLVIMENTO ECONÔMICO DO JAPÃO: DO GÉNESE AO CHAMADO MILAGRE ECONÔMICO
}

\begin{abstract}
Resumo
O objetivo deste artigo é estabelecer a origem e a evolução do desenvolvimento econômico de Japão no século vinte, em particular na época do chamado milagre econômico japonês. Para tal fim faz-se uma descrição histórica das reformas educativas, políticas e econômicas estabelecidas desde a era Edo até a década de 1970, bem como das diferentes conjunturas econômicas e políticas que recaíram sobre o Japão durante o período de 1945-1970 XX. Conclui-se que para entender o desenvolvimento econômico do Japão é necessário analisar as mudanças sociais, políticas e econômicas ocorridas no país durante o século XIX e, em particular, o papel do Estado e dos grupos empresariais na inserção da economia japonesa nos mercados internacionais.
\end{abstract}

Palavras chave: Desenvolvimento econômico; Política industrial; Planejamento; Reformas; Crescimento econômico.

Correa, F. (2017) Desarrollo económico de Japón: de la génesis al llamado milagro económico. En: Revista de la Facultad de Ciencias Económica: Investigación y Reflexión. rev. fac.cienc. econ, XXV (1). DOI: http://dx.doi.org/10.18359/rfce.2654

JEL: O11, O25, O43.

\section{Introducción}

Al final de la segunda guerra mundial, la economía japonesa se había desplomado. Sin embargo, luego de iniciado el periodo de reconstrucción Japón emprendió un rápido proceso de crecimiento económico hasta llegar a principios de la década de 1970 a la cumbre del crecimiento y, por tanto, al logro de un alto nivel de desarrollo económico, llamado en la literatura económica el "milagro económico de Japón”. Hoy Japón es a pesar de su estancamiento en términos de crecimiento económico en los últimos veinte años una de las grandes potencias de la economía mundial. En años recientes esta experiencia de Japón ha sido de interés para muchos países en desarrollo, en particular para los que están enfrentándose a dificultades causadas por la reformas económicas y políticas basadas en el "Consenso de Washington" y que buscan esforzarse para lograr un crecimiento económico con dinamismo y equidad. Como el desarrollo económico de Japón ha sido un resultado de una sinergia compleja de diversas causas, es difícil señalar un factor como la única razón ya que se interrelacionan todas las variables internas y externas: una política industrial planteada desde mediados del siglo XIX, una fuerte intervención del Estado en los asuntos económicos y sociales, un expansionismo militar que obtenía territorios (lo cual aseguraba una abundancia de recursos para desarrollar la base industrial del país), una política educativa, iniciada cien años antes, que garantizaría la adecuada transferencia de tecnología desde los países ya desarrollados de occidente, un sector empresarial en condiciones de competencia monopolística con aprovechamientos de economías de escala desde la segunda década del siglo XIX, entre otros factores.

Así el objetivo de este trabajo es describir la génesis y evolución del desarrollo económico de Japón entre la II guerra mundial y la década de 1970, época del llamado milagro económico japonés. Para esto se hará una descripción de las reformas educativas, políticas y económicas establecidas desde la era Edo hasta la década de 1970, así como de las diferentes coyunturas económicas y políticas que 
recayeron sobre Japón durante las siete primeras décadas del siglo XX. Por tanto, este artículo en su primera sección presenta los principales cambios sociales, políticos y económicos de la era Edo, en la cual se dieron los primeros pasos hacia el logro de una nación más educada y orientada a ampliar los mercados nacionales. En la segunda sección, se establece la evolución económica, política y social de la era Meiji, periodo en el cual se abrió el país al mundo occidental y se iniciaría el primer proceso de industrialización del Japón. La tercera sección, describe la traza de la política económica desarrollada en el periodo de las dos grandes guerras (19181945). Por su parte, la cuarta sección detalla los acontecimientos políticos y la evolución de la política económica y el entorno económico mundial en el periodo del rápido crecimiento japonés (19531970). La quinta sección analiza las características del modelo económico de Japón y destaca los elementos particulares de dicho modelo. Por último, la sexta sección recoge las principales conclusiones del trabajo.

\section{Antecedentes: la economía del Japón en el período Edo o Tokugawa}

Para entender la evolución de la economía japonesa en el siglo veinte es necesario conocer cómo transcurrió el Japón en los tres siglos anteriores. El período desde el año 1600 y el inicio del siglo XX comprende dos siglos y medio de profundos cambios políticos, económicos y sociales que modificarían el pensamiento en Japón, su escala de valores, su comportamiento social y sus instituciones (Collantes, 2008, p. 2).

En particular, esta época se divide en dos fases, a saber: El periodo Edo o Tokugawa (1603-1868) y el periodo de la Restauración Meiji (1868-1914). Las condiciones necesarias para el despegue del desarrollo económico japonés están soportadas en los cambios que se dieron durante estas dos hegemonías gubernamentales. A continuación se establece una caracterización de los principales cambios sociales y económicos acaecidos en el periodo 16031868. En la segunda sección se plantean los principales cambios económicos y políticos ocurridos durante la era de la Restauración Meiji.
Para Collantes (2008), entre el siglo V y el siglo XII Asia oriental era la región más dinámica de la economía mundial. En especial, entre el siglo $\mathrm{V}$ y el XII mientras Europa vivía un fuerte feudalismo y un estancamiento social, económico y tecnológico, las civilizaciones asiáticas como india y la china presentaban economías más dinámicas y con mayor avance tecnológico. Para finales del siglo XIX, era ya occidente el continente que había tomado la delantera y había impulsado el progreso económico mucho más que cualquiera de las economías asiáticas (Collantes, 2008, p. 1). Para Collantes (2008) es difícil establecer cuando se produjo esa brecha. Según este autor algunos hablan que fue aproximadamente por los años de 1500, cuando se dio la expansión europea hacia otros continentes y el surgimiento de una economía de mercado en Europa.

Para otros la divergencia entre los dos continentes se dio con el surgimiento de la revolución industrial, es decir en un periodo posterior a 1750. En cualquier caso sólo la economía japonesa inicio un proceso similar de desarrollo económico al emprendido por los países europeos (Nishijima, 2009).

Sin embargo, Ohno (2006) plantea que la historia del desarrollo económico de Japón se inicia antes de su primera industrialización, acaecida entre 1868-1914. Durante los dos siglos precedentes a este primer proceso de industrialización el país presento un dinamismo importante en la agricultura y la manufactura y avanzo en el desarrollo de sus mercados internos. Un dinamismo que perduró hasta principios del siglo XIX. Desde el punto de vista político Japón estuvo dominado por un gobierno samurai desde el siglo XII hasta el siglo XVII (Ohno, 2006). Luego de muchas guerras y rebeliones internas es el líder Tokugawa Ieyasu quien logra imponer una hegemonía gubernamental que perduraría hasta la época denominada La Restauración Meiji en 1868 (Ohno, 2006, p. 24)1. Durante el periodo Edo se establecieron las condiciones necesarias

\footnotetext{
Zalduendo (1995, p. 19) plantea que en el interior del Japón, durante el período Edo, se habían registrado más de 3000 revueltas campesinas y urbanas, generalmente causadas por el aumento del precio del arroz o por hambrunas locales.
} 
para la consolidación de la primera etapa de la industrialización de la economía japonesa ${ }^{2}$. Ohno (2006, p.23) plantea que en este periodo se crearon las condiciones internas para la industrialización inicial de Japón, las cuales las resume en: i) Unidad política y estabilidad, ii) Desarrollo de la agricultura, iii) Desarrollo del transporte y de los mercados internos, auge del comercio, las finanzas y la clase comerciante, iv) Crecimiento de las primeras manufacturas y, v) Elevación del nivel de educación.

En general, el gobierno central samurai era un gobierno de castas caracterizadas por la educación y estatus, a saber: Daimyo (clase gobernante), poseedores de gran cantidad de tierras que gobernaban libremente; eran señores feudales controladores de la vida social y económica al interior de sus tierras. Luego seguían los samurái de menor nivel los cuales estaban al servicio de los samurais Daimyo. Otra clase eran los campesinos los cuales conformaban la base económica del país pues representaban cerca del 90\% de la población de Japón (Ohno, 2006, p. 25). Por último se encontraban los artesanos y comerciantes, que eran el $13 \%$ de la población total y habitaban las ciudades que se habían conformado en torno a los castillos (los burgos en el contexto del desarrollo capitalista), quienes como clase social se desarrollaron notablemente gracias al impulso del gobierno central, el cual buscaba el crecimiento comercial del país.

Por otra parte, el gobierno central obligaba a los grandes poseedores de tierras a tener su residencia permanente en la capital (Edo) durante un periodo de seis meses y luego uno o dos años en sus tierras, según fuera la cercanía de las tierras de estos señores feudales a la ciudad capital Edo. Así, los señores feudales debían gastar importantes sumas de dinero en desplazamiento y en mantener a familias y sirvientes en la capital (Ohno, 2006 p. 26). Para Ohno (2006) una consecuencia económica importante para el país de esta directriz del gobierno central es que se generó una migración masiva de personas hacia la capital Edo, con los consecuentes avances en el sistema de

2 No obstante, según Ohno (2006), durante la hegemonía Totugawa hubo fuerte presión sobre el pensamiento japonés, sobre su escala de valores, su comportamiento y también sobre sus instituciones. transporte, tanto terrestre como marítimo. Este autor plantea que este fenómeno ocurrió en forma especial entre las ciudades de Osaka y Edo pues desde las grandes propiedades agrícolas de los señores feudales (samuráis Daimyo) se enviaban grandes cantidades de arroz a Osaka, la cual era la ciudad intermedia en el tránsito hacia la capital Edo y en donde se almacenaba y se vendía el arroz para mantener los gastos de la familia en Edo. Lo anterior implico un desarrollo comercial muy importante para Osaka.

Por tanto, Osaka se convirtió en una ciudad comercial y un centro financiero que, además, fue la primera ciudad del Japón donde se originó un mercado de futuros de arroz; en tanto que Edo era el centro político y un gran mercado interno para el consumo.

De otro lado, desde el punto de vista económico, el principal sector de Japón para la época era la agricultura. La sociedad de Edo era agraria ya que cerca del 90\% de la población del país era campesina a principios del periodo; aunque fue disminuyendo paulatinamente dicha proporción en la medida que se fue incrementando la dinámica de comunicación y comercialización interna de productos, lo cual condujo a la necesidad por productos con cierto grado de manufactura (Ohno, 2006).

La unidad básica de producción agrícola era la familia, aunque en principio una familia de agricultores usualmente estaba integrada de grupos de personas con muchas familias y sus siervos. Pero luego el gobierno obligó al desmantelamiento de los grandes grupos de familias para dejar solo la pequeña unidad agrícola familiar. Según las leyes gubernamentales del periodo los campesinos no tenían derecho a circular libremente y estaban atados a la tierra como fuerza de trabajo y como una base para el cobro de impuestos (Ohno, 2006, p.26), lo cual incentivó la movilización de algunos agricultores a otras tierras motivados, principalmente, por la presión impositiva y por la presión política y, en algunos casos, para mejorar su vida.

A partir del surgimiento de las primeras aldeas se dio la organización de éstas y se permitió cierta autonomía teniendo como condición el pago de impuestos (en especie, arroz), bajo control del gobierno local. 
Este impuesto sobre el arroz se le fijaba a las aldeas y no a los agricultores individuales (Ohno, 2006, p. 26). Los líderes de las aldeas, surgidos de la misma actividad agrícola, eran los encargados de establecer las cargas fiscales a los miembros de la comunidad. Así, tales líderes eran quienes desempeñaban el papel de la administración tributaria en el nivel local en el Japón del período Edo. Este esquema de gestión impositiva disminuía ostensiblemente los costos de administración del recaudo de impuestos por lo que lograba aumentar los ingresos netos fiscales (Tanaka, 2000, citado por Ohno, 2006). Así, establece una especie de descentralización administrativa que fue eficiente en el logro de resultados fiscales para el gobierno samurái.

Para Tanaka (2000, citado por Ohno (2006), "los agricultores eran muy dinámicos e independientes y, usualmente rechazaban políticas de los funcionarios gubernamentales cuando creían que eran irrazonables". Según Ohno (2006, p. 26) el gobierno bakufu (gobierno central) no tenía una verdadera política pública a largo plazo, sus leyes eran simples reglamentos que surgían como respuestas prácticas a los cambios históricos en curso que no podían ser detenidos.

En síntesis, en el periodo Edo la actividad agrícola avanzo de forma importante. En primer lugar, desde la mitad del siglo XV hasta los albores del siglo XVII se dio un aumento importante de la tierra cultivada (en esencia, en cultivos de arroz) y se emprendieron grandes proyectos de riego que llevaron a un aumento significativo de la producción agrícola. En la segunda etapa, desarrollada en el siglo XVIII, la superficie cultivada apenas si aumento pero hubo mayor utilización de herramientas, fertilizantes que condujeron a una productividad media mayor en todas las tierras agrícolas del País (Ohno, 2006, p. 38).

El incremento del comercio entre las dos grandes ciudades teniendo como precedente el avance de la agricultura en las tierras de los señores feudales generó el surgimiento de una agricultura comercial y una naciente industria artesanal lo cual, para el fin del periodo Edo, obtuvo como resultado aldeas que pasaron a ser pequeñas ciudades con cierto desarrollo económico y con un alto grado de comercio entre ellas (Ohno, 2006) ${ }^{3}$.

Ahora bien se plantea que durante el periodo Edo la política gubernamental hacia el comercio y la industria fue variable e inconsistente (Ohno, 2006, p. 31). Ohno (2006) afirma que en unas ocasiones el gobierno central buscó regular y gravar con impuestos las empresas privadas, y en otras su objetivo parecía ser incentivar una economía libre. Del mismo modo, en algunas situaciones el gobierno apoyó la cartelización en los mercados, otras veces los prohibió.

Por tal razón se argumenta que no hubo una política consistente a lo largo del periodo; simplemente se actuaba frente al devenir económico y las situaciones sociales y políticas de coyuntura. Los historiadores económicos aún debaten si la economía en el periodo Edo fue más dinámica en el contexto de la actuación de la política de libre mercado o bajo la política que incentivaba la formación y fortalecimiento de carteles empresariales. Según Miyamoto et al. (1995, citados por Ohno, 2006), el buen desarrollo de la economía de mercado depende de una serie de instituciones y costumbres tales como los contratos de intercambio y el crédito para facilitar las transacciones.

Desde esta perspectiva, estos autores defienden a los carteles durante el periodo Edo pues para ellos éstos fueron un mecanismo privado para generar este tipo de servicios financieros básicos para dinamizar las transacciones de mercado y, con ello, la economía del país.

De forma similar, desde una perspectiva de análisis institucional histórico, Okazaki (1999) muestra que el PIB estimado creció más rápido durante el tiempo en que se favoreció a los cárteles que cuando fueron restringidos. Este autor plantea que en la actividad del comercio los carteles fueron más bien un factor positivo y no un factor restrictivo para el desarrollo de la economía del país durante el periodo Tokugawa. No obstante, los datos disponibles y las estimaciones econométricas realizadas arrojan unos resultados cuya significancia estadística es muy débil

3 Según Collantes (2008) y Ohno (2006), el centro de actividad económica fue moviéndose paulatinamente desde Osaka y Kioto hacia a Edo. 
para ser concluyentes en este sentido (Tello, 1964).

Ahora, se cita frecuentemente a la educación como una de las causas centrales de la rápida industrialización en los períodos que le siguieron al período de Tokugawa (Ohno, 2006, p. 33). En esta fase de la vida de Japón la educación fue pasando del estudio de la antigua filosofía y literatura china en las escuelas públicas a pasar a estudiarse en las escuelas privadas. Este tipo de educación era común en todo el país y no era exclusiva de la ciudad capital Edo o de Osaka en las cuales estaba el poder político y económico.

\section{La era de la Restauración Meiji: el fin del aislamiento de la economía japonesa}

\subsection{Los antecedentes}

En la era Tokugawa Japón estuvo, en esencia, aislado de toda influencia exterior. Solo los comerciantes chinos y holandeses estaban autorizados a tratar con Japón (Ohno, 2006).

Según Ohno (2006, p. 40): "Para ello el contacto se restringió a una pequeña isla artificial, llamada Dejima, en Nagasaki, el resto de las transacciones comerciales estaban estrictamente prohibidas, tampoco había libertad de movimiento y los japoneses no podían entrar ni salir del país. Ante este aislamiento la única vía de acceso al conocimiento de occidente fue a través de los libros científicos y de medicina holandeses".

No fueron pocos los países que buscaron sin éxito entrar a la vida económica y social de Japón a través de la amenaza militar. Luego, el gobierno se vio obligado, ante la presión externa e interna, a la apertura comercial con los países occidentales y se firmaron diversos tratados de comercio ${ }^{4}$. De igual

4 Según Ohno (2006, p. 35) "el nacionalismo xenófobo fue muy intenso en un principio, pero Japón se dio cuenta de que occidente era mucho más moderno y poderoso y las luchas internas se centraron en cómo acabar con el bakufu y establecer un nuevo gobierno, regido por jóvenes samurái”. forma, se permitió la entrada a extranjeros para asentarse en el país, básicamente comerciantes y técnicos. En el inicio de la segunda mitad del siglo XIX se sucedieron una serie de presiones de diferentes feudos que desencadenaron guerras civiles y, en la última guerra acaecida entre 1867 y 1869, es derrotado el shogunato Tokugawa y es finalmente unificado el país. Edo fue rebautizado como Tokio y en esta ciudad se estableció la corte de Mutsuhito (Zalduendo, 1995, p. 20). Así, en el año 1868 comenzó el período conocido en la historiografía japonesa como Restauración Meiji que se caracterizó por establecer reformas políticas, económicas, sociales y culturales muy importantes para lo que sería el desarrollo económico japonés.

Para el nuevo gobierno el objetivo central era la modernización del país y la apertura social y económica a los países occidentales, es decir, la occidentalización de Japón (Ohno, 2006). Según ohno (2006), el slogan del país era "país rico, armada fuerte". De este modo se inició la búsqueda de la industrialización, el establecimiento de una nueva constitución política y una nueva organización legislativa del país y la expansión territorial. Se empezó por desarticular el sistema de castas y la apropiación por parte del gobierno de las tierras de los samurais feudales para lo que se utilizaron bonos del gobierno a cambio de éstas ${ }^{5}$.

\subsection{Sistema político, educación y política exterior en la era Meiji}

Con respecto al sistema político el objetivo central del gobierno Meiji era establecer un parlamento y una constitución. Se discutieron dos tipos de constitución: una de avanzada similar a la constitución británica y otra moderada como la constitución de Alemania. El gobierno encargo a expertos políticos para estudiar ambos modelos y, finalmente, en 1889 se estableció la constitución de Japón basada en el modelo alemán. Luego al año siguiente se estableció el parlamento (Ohno, 2006).

\footnotetext{
5 La alta inflación del periodo devaluó notablemente el valor de los bonos empobreciendo a los samurais y a los daimyo (Ohno, 2006).
} 
Ahora, la Restauración Meiji cambio tanto el sistema político y el régimen de tenencia de la tierra como el sistema de educación japonés. Así creó un mejor entorno para obtener la tecnología y las formas de organización y operación que se estaban desarrollando en occidente. En este sentido, Zalduendo (1995, p. 20) plantea que "para construir ferrocarriles, el sistema telefónico y de distribución de gas se establecieron contratos de hasta 10 años a 400 ingenieros y técnicos ingleses; otros sectores se distribuyeron entre holandeses (puertos y canales), alemanes (plantas químicas y franceses (hilados de seda y equipamiento militar)". Estos profesionales extranjeros fueron asignados a fábricas creadas por el Estado donde tenían asistentes nacionales lo cual permitiría en el mediano y largo plazo la transferencia de experiencia y conocimiento. Por otra parte, se estableció el sistema de educación obligatorio, además de la creación de universidades e institutos tanto públicos como privados. Así mismo, entre los años 1871 y 1873 se enviaron estudiantes japoneses a países de occidente con el fin de mejorar sus niveles de educación técnica profesional.

Para la década de 1880 Japón tenía profesionales con la capacidad de dirigir las empresas y los sectores de servicios públicos del país (Zalduendo, 1995) ${ }^{6}$. Lo anterior condujo a que en esta misma década fueran privatizadas muchas de las empresas públicas creadas 12 años antes (como astilleros, minas de cobre, plantas químicas, fábricas de maquinarias, etc. $)^{7}$. Según Zalduendo (1995, p. 21) a gran parte de estas empresas se les conoce hoy en Japón como las bisabuelas: Mitsubishi, Mitsui, Sumitomo, Kawasaki, Furukawa y Yasuda. Se afirma que el rol

6 Para Ohno (2006, p. 80), debido al alto costo de los técnicos extranjeros el gobierno decidió formar sus propios ingenieros enviándolos a estudiar a Europa y a Estados Unidos. Se creó un instituto de tecnología en Tokio para formar ingenieros de alto nivel, que posteriormente trabajarían para el ministerio de industria y para las principales empresas privadas seleccionando el tipo de tecnología que debía ser importada, comprando máquinas que luego ajustaban a los requerimientos y peculiaridades del país, y generando finalmente una tecnología híbrida, parte importada, parte adaptada y parte mejorada.

7 Las empresas del Estado se vendieron muy por debajo de su valor a hombres de negocios influyentes lo que causó un escándalo político en 1881 . central en el proceso de industrialización fue llevado a cabo por grandes grupos empresariales conocidos como zaibatsu, los cuales siguieron siendo apoyados por el Estado y lograron su máximo apogeo al finalizar la II Guerra Mundial, cuando dichos grupos fueron divididos y reorganizados de diferente forma por las autoridades estadunidenses en el Japón.

Con relación a la política exterior, Japón tuvo una guerra con China en 1894 en la cual venció y le impuso un tratado con condiciones rigurosas, donde lo más relevante fue el despojo de territorios como la península de Liaodong y la isla de Taiwan, la cesión de cuatro puertos y una indemnización en efectivo. Además, otra imposición fue la dejar a Corea libre, la cual pasaría al poco tiempo a ser un protectorado japonés y, en 1910, se anexaría a su territorio. Así mismo, Japón se enfrentó a Rusia por Manchuria y, luego de varias confrontaciones militares, lo derroto (Zalduendo 1995, p. 21).

Esta política expansionista le significo a Japón el acceso a fuentes abundantes de recursos naturales, lo que fue vital para el proceso de industrialización sucedido en la era Meiji. Estos territorios externos anexados, fruto de la política militar expansionista, ayudaron a formar los capitales monopólicos de los grupos empresariales Zaibatsu que funcionaban como holdings liderados por familias.

\subsection{Evolución de la política industrial}

En el contexto de la actividad económica el comercio con el mundo exterior durante la era Meiji se asociaba a la importación de textiles, equipos y maquinaria. En un principio se importaba el producto terminado desde Gran Bretaña y de India pero a medida que la industria nacional textilera iba desarrollándose disminuía la importación de textiles y se aumentó la importación de productos intermedios hasta llegar sólo a la importación de la materia prima (Ohno, 2006). Finalmente, se pasó a la importación sólo de maquinaria, equipos pesados desde Europa.

Por tal razón, Ohno (2006, p. 41) afirma que el esquema de comercio exterior con occidente era, en principio, la de un país en desarrollo exportando alimentos y bienes primarios, como hilo de seda, té, 
pescado, arroz, carbón, cobre y algunos productos artesanales como cerámica y lacas e importando manufacturas de consumo y bienes industriales. Todas estas importaciones ocasionaron graves problemas en la balanza comercial de Japón. Más tarde el surgimiento de la industria pesada conduciría a disminuir el déficit comercial del país (Teranishi \& Kosai, 1993).

De otro lado, el desarrollo económico de Japón hasta la primera guerra mundial presentó dos aspectos fundamentales: por una parte un fuerte aumento de la actividad financiera, la industria pesada, marina y las empresas coloniales $y$, por otra parte, una modernización y diversificación de la industria tradicional y de la agricultura (Ohno, 2006, p.56). Estas últimas continuaban siendo prioritarias tanto para abastecer a la nueva industria como al mercado doméstico, a la vez que proporcionaban los recursos necesarios, vía exportaciones, para financiar las importaciones de equipos, materias primas alimentos.

Ohno (2006) plantea que el gobierno Meiji jugó un rol muy importante en la promoción industrial al crear empresas en la industria pesada, a pesar que en principio fueron las industrias ligeras las que se desarrollaron primero (en particular, la industria algodonera japonesa se convirtió en una de las industrias más importantes en el mundo en el siglo XIX y principios del siglo XX). Para inicios del siglo XIX Gran Bretaña dominaba el mercado mundial de textiles. Ahora bien, Japón se fijó como meta sustituir las importaciones de tejidos provenientes de Gran Bretaña y de India. Como ya se describió antes, con ayuda del gobierno, en conjunto con la iniciativa del sector privado, se construyeron fabricas modernas a partir de la adopción de las últimas tecnologías traídas de Europa (Ohno, 2006, p. 57) . $^{8}$

En la industria pesada, en principio, dominó la producción de las empresas militares propiedad del Estado. En particular, se destacaron la industria naviera y la metalúrgica, ésta última mucho más compleja de establecer y cuyos actividades se orientaron hacia la expansión y modernización de la industria

\footnotetext{
A principios del siglo XX Japón ya era uno de los mayores exportadores de tejidos de algodón, en su mayor parte a China (Ohno, 2006).
}

minera en la cual Japón poseía cobre y carbón (Zalduendo, 1995). En los inicios del periodo Meiji la mayoría de la maquinaria era importada ya que la producción local era de baja calidad. Después se establecieron pequeñas y medianas empresas que se concentraron alrededor de Tokio y Osaka, lo que llevo a que nacieran distritos industriales los cuales producían básicamente piezas y dispositivos (Ohno, 2006, p. 78). Como ya se anotó antes, toda esta modernización industrial no hubiera sido posible sin un intenso proceso de transferencia de tecnología.

\subsection{La política económica del periodo Meiji}

En el aspecto macroeconómico de Japón se destacan varias etapas durante la era Meiji (Ohno, 2006, p. 58). Una primera etapa, desde 1850 hasta finales de 1870, donde se registra de impacto inicial del comercio exterior. Se plantea que la tecnología y los productos de occidente produjeron cambios en los precios relativos y en la estructura industrial de Japón y, además, fue un periodo de inflación promedio anual fue alta. Una segunda etapa que se caracterizó por presentar una tanto confusión monetaria e inflación creciente (toda la década de 1870). En esta etapa la inflación se aceleró debido al aumento en la impresión de papel moneda para financiar una guerra civil iniciada en $1877^{9}$. Seguidamente una tercera etapa, entre 1880 y 1884 , se caracteriza por la deflación. El Gobierno japonés adoptó una política deflacionaria para terminar la inflación $e$ introducir un sistema monetario moderno. Esto incluyó la creación del Banco de Japón como un banco central en 1882. Como consecuencia de ello los ingresos rurales disminuyeron y el número de agricultores sin tierra se incrementó.

Siguió una cuarta etapa llamada el tiempo del primer boom empresarial, hacia finales de 1880. Después que se subsidió la inflación y se estableció la banca moderna hubo una oleada de creación de empresas privadas bajo el marco jurídico de las sociedades anónimas (empresas por acciones). Ahora,

\footnotetext{
9 A medida que los precios del arroz y otros productos agrícolas subían los agricultores y terratenientes se enriquecían mientras que los antiguos samurais se hacían más pobres (Collantes, 2008).
} 
la depreciación del tipo de cambio y las bajas tasas de interés también incentivaron la el surgimiento de dichas sociedades. Después de este tiempo se sucedieron olas continuadas de auges empresariales. Se estableció un gran número de sociedades por acciones adicionales entre finales de la década de 1890 y finales del año 1900 y durante la primera guerra mundial; olas que fueron sólo interrumpidas por recesiones ocasionales ${ }^{10}$.

Finalmente, se habla de una quinta etapa de activismo fiscal que se desarrolla en tiempos de entre guerra (entre Japón y China desde 1894 hasta 1895; Japón y Rusia desde 1904 hasta 1905). En tales periodos se adoptó el activismo fiscal. La inversión pública se llevó a cabo para construir, por ejemplo, los ferrocarriles y la red telefónica nacional (Ohno, 2006). El gasto militar se mantuvo incluso en tiempos de paz. Por su parte, se inició la gestión económica de Taiwan una colonia adquirida en 1895, a través de la creación de instituciones y de la realización de inversión pública. De otro lado, los gobiernos locales emitieron bonos en moneda extranjera con el fin de invertir en acueductos, carreteras, educación, etc. Como resultado de lo anterior el tamaño del gobierno (la suma del gobierno central con los gobiernos y locales) se aumentó y el déficit de balanza de pagos se amplió. Las reservas de oro (es decir, las reservas internacionales) se fueron disminuyendo paulatinamente y la proporción entre deuda y PIB se incrementó a 40\%. Cerca del $50 \%$ de la deuda pública estaba en moneda extranjera (Ohno, 2006).

Desde finales del periodo Meiji en adelante, el gobierno de turno promovió el activismo fiscal. La base de apoyo principal del gobierno en ese momento estuvo integrada por los agricultores y propietarios de tierras ricos que deseaban una política de inversión pública dinámica en las zonas rurales. Sin embargo, el gasto público en exceso condujo a una creciente presión negativa sobre la balanza de pagos lo que llevaría a instaurar un apretón fiscal que redujera el

$10 \mathrm{Al}$ principio, estas empresas por acciones se concentraron en las industrias de textiles y de ferrocarriles. Luego, la creación de este tipo de empresas se extendió a todos los sectores de la economía (Ohno, 2006). déficit público y, por tanto, la presión negativa sobre la balanza de pagos (Ohno, 2006). Así, la industrialización, el alto crecimiento del gasto gubernamental y el fuerte gasto militar generaron presiones negativas sobre la acumulación de capital en el país y, por tanto, produjeron un déficit crónico en la balanza de pagos. Esta presión condujo a que el gobierno tuviera que financiar cada vez más el gasto con bonos colocados en los mercados externos. Así, para el periodo 1910-1914 Japón había perdido más del $20 \%$ de sus reservas de oro lo que lo dejaría aportas de una crisis financiera en las proximidades de la primera guerra mundial (Collantes, 2008, p. 13).

Según Collantes (2008) para la primera década del siglo XX los impuestos absorbían casi el 30\% del ingreso del campesino medio en comparación al $14 \%$ del ingreso medio de un empresario industrial o comercial, lo que indica una alta transferencia de recursos desde la agricultura hacia los sectores industrial y comercio.

Ahora bien, dada la importancia del sector agrícola para el crecimiento urbano del país y mantenimiento de la cohesión social, el gobierno Meiji busco incentivar la senda del crecimiento de este sector pero utilizando procesos intensivos en mano de obra y no con alto componente de capital, que necesariamente llevaría a desplazamientos de mano de obra del campo a las ciudades. Así la política agraria desarrollada en ese periodo en Japón buscaba un crecimiento agrario constante a la vez que mantenía la cohesión social, por lo que no se fomentaron los grandes latifundios agrícolas debido a su estrecha vinculación con un nivel tecnológico alto y a grandes economías de escala en la producción ${ }^{11}$.

\section{La economía japonesa entre 1914 y 1945}

\subsection{Antecedentes}

Puede afirmarse que el desarrollo industrial de Japón lo planeó y consolido en su mayoría el Estado.

11 Lo que se busco fue fortalecer las unidades agrícolas familiares de pequeños y medianos arrendatarios. 
Cuando se superaron los obstáculos, principalmente en términos de la insuficiencia del mercado, el Estado entregó las industrias ya antes nacionalizadas a los grandes grupos empresariales (Zaibatsu). Así, se establece que el desarrollo industrial del Japón, en su primera etapa, se basó en el mercado interno. Sólo después de obtener un tamaño de mercado importante el mercado de exportación jugó el rol central del crecimiento económico de la economía japonesa (Tello, 1964). Desde el lado político se plantea que para finales del periodo Meiji los vínculos entre la política y las fuerzas militares eran muy fuertes gracias a que la expansión territorial lograda por éstas últimas facilito el mayor acceso a recursos abundantes, tan necesarios para el surgimiento de la industrialización, que era uno de los intereses centrales del gobierno Japonés. De igual forma, se estrecharon los vínculos entre el Estado y los grandes grupos empresariales. Por último, en términos macroeconómicos, este proceso descrito antes condujo a que a inicios de la primera guerra mundial Japón tuviera un Estado grande, quizás con un gasto excesivo, un déficit de balanza de pagos importante y una deuda pública alta en proporción al PIB.

\subsection{La evolución de la economía entre 1918 y el estallido de la segunda gue- rra mundial}

Japón participó en la primera guerra mundial como uno de los países aliados. En la Conferencia de París de 1918 obtuvo, como compensación, los territorios en posesión que tenía Alemania, China y las pequeñas islas Marianas y Carolinas del océano pacífico suroccidental (Zalduendo, 1995, p. 21).

Ahora bien, esta guerra genero impactos positivos y negativos para el país. Primero, hubo importantes limitaciones para la importación de bienes finales y de capital requeridos para consolidar el proceso de industrialización iniciado varias décadas antes. Lo anterior se debió a que sus proveedores europeos estaban en guerra lo cual imposibilito las exportaciones de tales bienes hacia Japón (Ohno, 2006). Sin embargo, la misma situación de guerra de estos países genero una alta demanda de los productos japoneses que, a pesar de su inferior calidad, sustituían a los productos europeos.
De esta manera, Japón paso de tener déficit en balanza de pagos durante la era Meiji a tener un superávit en dicha balanza lo cual llevo a que el PIB creciera a tasas del 10\% anual aunque igualmente el nivel de precios se duplicó. Así, el débil crecimiento de la inversión nacional fue compensado con los altos niveles de crecimiento de las exportaciones netas (Ohno, 2006, p. 100). Este proceso que surgió a partir de la primera guerra mundial condujo a un aumento en la sustitución de importaciones en las grandes industrias.

La sustitución de importaciones y, por supuesto, el alto crecimiento de las exportaciones causo un desplazamiento de la agricultura como sector primordial de la economía japonesa para dar paso al sector industrial. Este crecimiento en la industria movilizo grandes cantidades de población desde el campo hacia las ciudades incentivando un aumento importante del tamaño del mercado interno. Ahora bien, la primera guerra mundial llevo a un aumento generalizado del nivel de precios. En 1918 cuando terminó esta guerra se produjo un retroceso de la pequeña empresa en Japón. No obstante, la economía japonesa continuó estable hasta 1919, pero luego llegó una crisis. El comienzo de la recesión de la posguerra significó que estallara la burbuja generada por la situación de guerra lo cual llevo a que los precios de muchos productos básicos se redujeran significativamente y, como resultado, Japón se encontró ante una situación de deflación ${ }^{12}$.

El ajuste macroeconómico se produjo principalmente a través de los cambios de precios en lugar de ser a través de la fluctuación de la oferta de productos. Cuando la burbuja finalizo quedo en evidencia la falta de competitividad y el exceso de capacidad de la economía japonesa. Después de esto, y a lo largo de la década de 1920, el país pasó por una serie de recesiones y crisis bancarias. La más grave se produjo en 1927 momento en el que crecimiento del

\footnotetext{
12 En el año de 1920, el precio de los hilos de algodón se redujo en un 60\%, los de la seda en un 70\%, y el índice de la bolsa del mercado de valores japonés caía en un 55\% (Ohno, 2006, p. 102)
} 
PIB cayó notablemente con respecto al crecimiento de la primera guerra mundial (Ohno, 2005) ${ }^{13}$.

Ohno (2006) afirma que ante el inicio de un periodo de gran recesión es importante mirar cómo fue la reacción del gobierno japonés. Según este autor, el gobierno tenía dos opciones de política: i) Rescatar las industrias y los bancos debilitados que estaban con deudas incobrables y, ii) Eliminar las empresas ineficientes con el fin de racionalizar la economía, soportando el costo económico y social de esta transición. Así, afirma Ohno (2006, p. 103), el gobierno de Japón optó por la primera opción de política. En particular, el Banco de Japón concedió préstamos de emergencia a los bancos y a las industrias en dificultades para evitar más quiebras y desempleo. Esta política solucionó el problema en el corto plazo pero no eliminó el problema estructural de la economía, lo cual llevaría a una verdadera crisis económica varios años después.

En síntesis, en términos de crecimiento y desarrollo económico, para la década de 1920, el Japón había consolidado las bases de su industrialización, a pesar de la serie de crisis bancarias ocurridas a partir de la Primera guerra mundial hasta 1927. Antes de 1922 su tasa de crecimiento del PIB, aunque elevada, fue errática y estuvo sujeta a fluctuaciones cíclicas considerables (Tello, 1964, p. 561). Luego, se estabilizó debido, en esencia, a la consolidación de la industria y al gran aumento de las exportaciones. De 1926 a 1938, el producto nacional bruto real aumento más del 70\%. No obstante, a pesar del crecimiento real de la economía el índice de precios al productor bajó de 100 en 1925, a 74 en 1936 y los salarios reales aumentaron en el 15\% en el mismo periodo. Tales fenómenos agudizaron la concentración del ingreso pero trajeron a la vez incrementos de la inversión productiva. Según Tello (1964, p. 561) "la clase capitalista prefirió la

\footnotetext{
Según Ohno (2006, p. 102) "la consecuencia más importante de la crisis bancaria de 1927 fue la concentración financiera. Después de la crisis, el gobierno disolvió y fusiono bancos poco sólidos en unas dos docenas de nuevos bancos en el periodo de un año. En este proceso, los ahorradores de los bancos en quiebra perdieron entre el 35 y el $50 \%$ de sus ahorros".
}

inversión al consumo y los asalariados, en la medida en que les fue posible, también ahorraron".

Durante la década de 1930, el Japón canalizó sus esfuerzos a la creación del Junsenji-Keizai (economía de quasi- guerra). Pero su nueva política económica a pesar que satisfacía en sus aspectos técnicos, en los parámetros de lo que ahora se conoce como una política de pleno empleo, se basaba en la industria militar en gran escala (Tello, 1964, p. 562). Por tanto, los asuntos económicos pasaron a manos de los militares.

Luego de salir de la crisis financiera después de 1934, al principio, para Japón las dos variables cruciales en la planificación en el tiempo de nuevas guerras eran las reservas de divisas y la disponibilidad de energía y materias primas y, obviamente, la capacidad en el transporte marítimo (Ohno, 2006, p. 137). De este modo, hasta 1940 la cuestión central de la economía japonesa fue cómo maximizar la producción militar sujeta a estas dos restricciones. Después de ese año Japón ya no podía comerciar con otros países y, por tanto, el problema ya fue el transporte de los recursos naturales desde las colonias japonesas y las áreas ocupadas militarmente (Ohno, 2006).

\section{II guerra mundial y el surgimiento del milagro económico japonés}

\subsection{Una recapitulación del crecimiento económico de Japón}

La industrialización moderna comenzó a impulsar a la economía japonesa a partir de la última década del siglo XIX y, desde ese periodo hasta el surgimiento de la II Guerra Mundial, Japón se aproximó a las economías más desarrolladas del mundo, aunque quizás muy lejos de tener un desarrollo económico similar a Estados Unidos. Al inicio de la década de 1940, la brecha de Japón con respecto a esos países era aún positiva, aunque el país llevaba más de dos décadas con altas tasas de crecimiento económico (Collantes, 2008). Sin embargo, este país empezaba a tener cambios estructurales que ya evidenciaban un grado importante de desarrollo económico. 
Así, disminuyó el empleo agrícola; se presentaron altas tasas de migración desde el campo a la ciudad, las cuales habían impulsado el aumento de la tasa de urbanización La tabla 1 evidencia la evolución del empleo agrario y el grado de urbanización del país.

Además, las exportaciones del país ya no estaban compuestas por bienes primarios y habían pasado a ser exportaciones industriales. Uno de los lemas de la restauración Meiji había sido "enriquecer el país, fortalecer el ejército", y eso fue lo que realmente ocurrió en Japón durante las décadas previas a la Segunda Guerra Mundial (Collantes, 2008, p. 2).

Tabla 1. Evolución del empleo agrario y los niveles de urbanización en Japón en el periodo 1890-1998

\begin{tabular}{|l|c|c|c|c|c|}
\hline \multicolumn{1}{|c|}{ Indicador } & $\mathbf{1 8 9 0}$ & $\mathbf{1 9 1 3}$ & $\mathbf{1 9 5 3}$ & $\mathbf{1 9 7 3}$ & $\mathbf{1 9 9 8}$ \\
\hline Empleo agrario (\%) & 70 & 63 & 39 & 14 & 5 \\
\hline Grado de urbanización (\%) & 12 & 18 & 56 & 78 & 79 \\
\hline
\end{tabular}

Fuente: Tello (1964).

\subsection{El resurgimiento de la economía japonesa}

La segunda guerra mundial le produjo a Japón pérdidas muy importantes del territorio apropiado militarmente en el pasado. Su capacidad productiva sufrió un descenso muy importante en todas sus industrias. Para 1945 la producción de la industria no se acercaba al 30\% de la producción del año 1935 (Ohno, 2006 , p. 145). Con respecto a la población, Japón perdió cerca de tres millones de personas y tuvo que repatriar aproximadamente a 6 millones de soldados (Ohno, 2006, p. 146). Según Ohno (2006) a pesar de que dos terceras partes del stock de maquinaria del país sobrevivió a los bombardeos de los aliados, las fábricas y los ferrocarriles no operaban por falta de energía y materias primas por lo que se afirma que la fuerte disminución en la producción no se debió tanto a la falta de capacidad como si a la falta de recursos energéticos y materias primas (Ohno, 2006, p.146).

Ahora bien, después de la derrota en la II guerra mundial todo el proceso de reconstrucción de la economía tuvo el acompañamiento del Mando Supremo de las Fuerzas Aliadas. En este sentido, el principal propósi- to de las fuerzas norteamericanas fue democratizar el sistema político y descentralizar la economía. Ohno (2006, p. 150) describe las tres grandes reformas que llevo a cabo Estados Unidos en Japón:

- Abolición de los grupos empresariales Zaibatsu: Para Estados Unidos tanto los grandes grupos empresariales como las grandes empresas comerciales eran los culpables del militarismo por su influencia y, por lo tanto, los veía como un obstáculo a la democratización del país. Así, los Zaibatsu fueron desarticulados y se establecieron empresas independientes lo cual condujo a una mayor competencia en la economía. Luego del retiro de Estados Unidos del territorio japonés en 1952, los antiguos Zaibatsu empezaron a asociarse de nuevo pero bajo una forma menos rígida denominada Keiretsu, la cual, sin embargo, no llego a tener el poder alcanzado antes de la guerra ${ }^{14}$.

- Reformas laborales: las nuevas leyes sindicales determinaban el derecho de organización sindical, el derecho de huelga y la participación en la negociación colectiva, así como condiciones laborales mínimas.

- Reforma de la tierra cultivable: se prohibió la tenencia de tierras si el propietario no estaba presente en ellas utilizándolas. De este modo, se expropiaron grandes extensiones de tierra que luego fueron vendidas a sus arrendatarios por precios bajos, lo que llevó a un aumento de la población de agricultores propietarios de tierras. Este aumento del número de minifundios condujo a que la productividad de las explotaciones agrícolas disminuyera.

Ahora, para atacar la inflación y estabilizar a la economía japonesa, el gobierno de Estados Unidos envió a Tokio al presidente del Banco de Detroit, J. Dodge, quien llevo a cabo una serie de políticas económicas estabilizadoras. Tres fueron las medidas más importan-

\footnotetext{
14 Keiretsu significa una red vertical para distribución de bienes que está integrada de fábrica de montaje. subcontratistas que suministran partes y componentes, y mayoristas y minoristas que venden el producto final (Nishijima, 2009, p.3).
} 
tes: i) la anulación de los subsidios y préstamos concedidos por el gobierno a las empresas; ii) la unificación del tipo de cambio del yen con respecto al dólar y, iii) un nuevo sistema impositivo basado, principalmente, en los impuestos directos (renta y sociedades). Las medidas de estabilización desarrolladas fueron efectivas ya que consiguieron la estabilidad de precios. De esta forma, la eliminación de los subsidios y el control de precios generaron efectos de tranquilidad en una economía altamente intervenida. No obstante, los efectos colaterales no se harían esperar. Como consecuencia la actividad económica rápidamente empezó a descender y el país no llego a la recesión gracias al estallido de la guerra de Corea (1950-1953) pues Estados Unidos utilizó a Japón como base de aprovisionamiento, lo que produjo un gran estímulo generado por la demanda externa, como sucedió durante la II guerra mundial (Ohno, 2006, p.158).

\subsection{El milagro económico (1953-1975)}

Lo que usualmente es conocido en la literatura como el Milagro económico Japonés se relaciona con el rápido crecimiento que tuvo Japón durante la postguerra, con tasas de crecimiento que en el periodo comprendido entre 1946 y 1973 fueron en promedio del 9,3\% y alcanzando niveles del 11\% durante la década de 1960 (Briceño, 2013 p. 3). La dinámica de la economía japonesa durante el periodo 1951-1973, fase en que se da el llamado milagro japonés, la sintetiza Briceño (2013, p.16):

"Hasta la crisis del petróleo de 1973, la economía japonesa evidenció una tendencia de crecimiento continuo, con una tasa de crecimiento anual promedio del PNB del $10 \%$, ligeramente menor durante los años 50 y algo por encima durante la década de 1960. Por su parte, la inversión en capital creció a un ritmo del 22\%. De otro lado, el incremento de la demanda doméstica junto a la alta tasa de inversión generó una expansión de la escala de la producción, lo que llevo a una mayor productividad del trabajo que, a causa de la abundancia de mano de obra, se asociaba a salarios bajos, con lo cual la competitividad en el mercado era mayor y permitía aumentar las exportaciones. Ahora, la economía japonesa experimentó ciclos, que estaban marcados por los déficits de la balanza de pagos. Las importaciones aumentaban cuando la producción se expandía, a consecuencia de una mayor inversión en plantas y equipos, un mayor consumo privado, aumento del gasto público y el crecimiento de los stocks para anticipar ventas. Pero, por otro lado, dado que los bienes eran canalizados hacia el mercado interno, a consecuencia del aumento de demanda, las exportaciones se restringían y la balanza por cuenta corriente era deficitaria".

Durante este periodo el contexto internacional también fue favorable para Japón en diversos aspectos. De un lado, el inició de la guerra fría condujo a que Estados Unidos utilizara el potencial industrial de este país con el fin de fortalecer su posición militar frente a la Unión Soviética. Así, el objetivo de Estados Unidos fue que Japón se convirtiera en la gran "despensa industrial" de Asia (Collantes, 2008).

Por otra parte, Estados Unidos abrió sus mercados a las exportaciones industriales de Japón y permitió una política de protección gubernamental japonesa frente a las empresas extranjeras. Lo anterior se tradujo en un boom de las exportaciones de Japón y en un mayor déficit comercial de Estados Unidos con éste. Según Collantes (2008), esto se daría en un contexto de turbulencias en el sistema monetario internacional que surgirían a principios de la década de 1970. Tal situación conduciría a una presión para la renegociación de los acuerdos comerciales entre los dos países con el fin de equilibrar la balanza comercial de Estados Unidos frente a Japón. En particular, se buscaba un proceso de apreciación de la moneda japonesa frente al dólar (Collantes, 2008, p. 16). No obstante, para principios de la década 1970 la economía japonesa era ya una gran economía comparable a las de Estados Unidos y a la futura Unión Europea. Es decir, había surgido el milagro económico japonés.

La tabla 2 muestra algunos indicadores de bienestar social que evidencian el alcance del desarrollo económico logrado en Japón durante el siglo XX. La 
esperanza de vida se duplico entre los años 1903 y 1998. Por su parte la tasa de mortalidad infantil del año 1998 representaba solo el 2.63\% de la tasa de inicios del siglo XX. Estos dos indicadores reflejan el potencial del aumento en la productividad de la mano de obra, o cual es vital para el logro de una tasa decrecimiento económico continuo en el largo plazo. Además, la generación y estabilidad del empleo es otro indicador destacado pues se pasa de una tasa de desempleo del 4\% en 1903 a una tasa de al 4\% en 1973. A pesar de que la tasa aumenta de nuevo para 1998, fruto del estancamiento del crecimiento económico, el mayor ahorro dela país durante el siglo XX le permitió a Japón mantener unas finanzas que garantizaron mantener los niveles de bienestar logrados en la época de máximo esplendor del período del milagro japonés.

Tabla 2. Indicadores de bienestar social de Japón en el siglo $X X$

\begin{tabular}{|l|c|c|c|c|}
\hline \multicolumn{1}{|c|}{ Indicador } & $\mathbf{1 9 0 3}$ & $\mathbf{1 9 4 8}$ & $\mathbf{1 9 7 3}$ & $\mathbf{1 9 9 8}$ \\
\hline $\begin{array}{l}\text { Esperanza de vida al nacer } \\
\text { (años) }\end{array}$ & 44 & 57 & 74 & 81 \\
\hline Mortalidad infantil (por mil) & 152 & 65 & 11 & 4 \\
\hline Estatura a los 18 años (cms) & 160 & 163 & 169 & 171 \\
\hline Tasa de desempleo (\%) & 4.0 & 1.9 & 1.4 & 4.1 \\
\hline
\end{tabular}

Fuente: Mosk (2007).

\subsection{Factores claves del crecimiento económico entre 1953-1975}

Los economistas aún discuten sobre la verdadera causa del elevado crecimiento económico en Japón durante el periodo establecido entre 1950 y $1970^{15}$. Algunos economistas keynesianos, como Yoshikawa (1997, citado por Ohno, 2006, p. 176), creen que la fuerza más importante fue el consumo robusto. Sin embargo, para Ohno (2006, p. 176) "es muy difícil señalar un factor como la única causa ya que se interrelacionan todas las varia-

15 El alto crecimiento económico de Japón llegó a su fin a principios de la década de 1970. Posteriormente, la tasa de crecimiento anual se redujo a un promedio de alrededor del $4 \%$ entre las décadas de 1970 y 1980 , y más tarde cayo a una tasa cercana a 0\% en la década de 1990 (Ohno, 2006, p.177). bles”. Según este autor, los factores claves del rápido proceso de crecimiento económico de Japón entre 1945 y 1970 son:

- Capital, el cual señala que fue el mayor responsable del crecimiento. Sus principales componentes, los equipos y las estructuras no residenciales, crecieron a tasas superiores al 9\% anual durante todo el periodo 1953-1971, incrementando el acervo de capital de la economía. Para conseguir este ritmo de crecimiento del stock de capital se necesitaron fuertes aumentos anuales de inversión, incrementos que fueron posibles gracias a los recursos disponibles, al ahorro y a la disminución del precio relativo de los bienes de capital, probablemente debido a la reducción en los costos de producción de los bienes de capital, equipos y de las estructuras no residenciales.

- Conocimiento: el segundo factor en importancia, tanto por su contribución como por su notable crecimiento lo constituyen los avances en el conocimiento, básicamente en tecnología, organización empresarial y capacidad de gestión. Para Ohno (2006, p.177) la contribución de este grupo de factores no es tan importante en el resto de los países desarrollados; quizás la razón sea que la tecnología y métodos de gestión que se utilizaban en Japón estaban muy atrasados respecto a los países desarrollados, produciéndose por lo tanto un fenómeno de "catching up" tecnológico y de métodos de gestión.

- Economías de escala: el crecimiento total de la producción hizo que fuera posible la expansión de los mercados (locales, nacionales e internacionales) para todos los productos, expansión que fue rápida y en particular grande en el caso de los bienes de consumo duradero, como los electrodomésticos, generando importantes beneficios derivados de dichas economías de escala.

- Trabajo: Aumentó el total de personas ocupadas, pues el empleo pasó de 39.4 millones en 1953 a 51.4 en 1971. Se amplió la jornada de trabajo semanal, en promedio se trabajaban semanalmente casi 9 horas más en Japón que en Estados Unidos en 1971. 
- Asignación de los recursos: durante este periodo se produjo una notable mejora en la asignación de los recursos, al reducir la proporción de trabajadores utilizados ineficientemente en la agricultura, auto-empleados y familiares no pagados en las pequeñas empresas no agrícolas. El empleo agrícola pasó de representar el 35.6\% de todo el empleo en 1953 al 14.6\% en 1971 (tabla 1), mientras que los auto-empleados y familiares no pagados en la pequeñas empresas no agrícolas bajaron del $22.5 \%$ al $18.8 \%$.

- Educación: el aumento en el nivel educativo de la población también constituyó un factor determinante en la calidad y nivel de calificación de los trabajadores, lo que permitió que pudieran absorber las nuevas tecnologías disponibles así como las mejoras en el sistema de producción y gestión; aunque su importancia fue notablemente menor que los otros cinco factores.

\section{El modelo de capitalismo y la gestión empre- sarial en Japón}

El modelo económico japonés desarrollado a lo largo del siglo veinte tiene cuatro componentes: i) el protagonismo de grandes conglomerados empresariales de carácter multisectorial, ii) la integración organizativa de la mano de obra que trabaja para tales conglomerados, iii) el dualismo en la estructura empresarial y los mercados laborales y, iv) un Estado intervencionista que estaba a la búsqueda de externalidades para proporcionar a la economía privada (Collantes, 2008 p. 16).

Para Collantes (2008, p. 17) el papel estelar en el capitalismo japonés lo tuvieron los grupos empresariales. Desde el inicio del proceso de industrialización, a finales del siglo XIX, el motor central del capitalismo japonés han sido los grandes grupos empresariales, cuya actividad se expande por distintos sectores, desde la construcción naval a la producción de acero, desde los textiles hasta los televisores, los coches y los computadores. Algunos de estos conglomerados surgieron con la privatización de empresas públicas deficitarias a finales del siglo XIX. Este liderazgo de los zaitbasu fue importante durante la primera mitad del siglo XX.

Apenas unos años después de la disolución formal de estos grupos empresariales por parte del gobierno de ocupación, en 1945, volvieron a formarse grandes grupos empresariales llamados Keiretsu. La época del milagro económico, al igual que la época de la convergencia económica previa a la II Guerra Mundial, fue protagonizada por los grupos empresariales japoneses. Fueron los keiretsu quienes impulsaron el crecimiento y la innovación en tecnología en sectores estratégicos, incluyendo los sectores exportadores que tanta importancia tendrían para el desarrollo del país. Se plantea que en Japón el modelo económico funcionó bajo el esquema Schumpeteriano: las grandes empresas operando en régimen de competencia imperfecta podían ser más dinámicas que las empresas pequeñas y medianas operando en régimen de competencia perfecta (Collantes, 2008, p.18).

De otro lado, aunque hay una polémica sobre si existe un único tipo de administración en Japón llamado "Administración de estilo japonés" no se puede negar que han imperado características únicas y destacadas en la gestión empresarial de Japón, especialmente en lo concerniente a la gestión del capital humano. El modelo de relaciones laborales vigente en los grupos empresariales japoneses, que buscaba una alta integración organizativa de los trabajadores, era una de las principales peculiaridades del capitalismo japonés (Collantes 2008, p. 19). Se presentaba (y aun se presenta) un compromiso de empleo permanente, en particular en las grandes empresas. Así los trabajadores no dejaban ni rechazaban cualquier trabajo (Nishijima, 2009, p. 3). Era común la institución del empleo permanente pues había un compromiso de la empresa a mantener al trabajador en su trabajo aun en situación de contracción de la demanda. Además, el salario estaba estrechamente relacionado a la antigüedad del empleado de modo que el salario de un trabajador de mayor edad estaba por encima del salario de trabajadores jóvenes.

Sin embargo, dicho salario también dependía del nivel educativo y de las características del puesto de trabajo ocupado. Pero, dejando estos factores cons- 
tantes, la edad se convertía en el principal determinante de los salarios. Además, la negociación de las condiciones de trabajo se desarrollaba a través de sindicatos de empresa. Según Nishijima (2009) este tipo de sistemas han consolidado la estabilidad del empleo teniendo como resultado una tasa de desempleo baja lo cual contribuyo, a lo largo del periodo de estudio, a las estrategias de inversión de largo plazo de las empresas.

Por último, se privilegiaba una toma de decisiones colectiva en el día a día de la empresa, de tal modo que no sólo los directivos o los gestores, sino también los trabajadores manuales, estaban integrados en una estrategia de identificación común de problemas y soluciones. Estos cuatro rasgos constitutivos del modelo japonés de relaciones laborales comenzaron a aparecer durante el periodo de entreguerras y se consolidaron definitivamente durante la era el "milagro" posterior a 1945 (Collantes, 2008, p.20).

La política gubernamental también jugó un papel importante en el impulso al desarrollo económico de Japón en el siglo XX ya que tener un control del sistema financiero a través de fuertes regulaciones. El objetivo central de dicha regulación fue garantizar que los grandes grupos empresariales tuvieran el acceso a grandes cantidades recursos de capital con costos bajos, para lograr las inversiones productivas necesarias en diversos sectores de penetración en mercados internacionales). Para esto el gobierno otorgo un poder de mercado a pocos bancos que tenían vínculos de largo plazo con los zaibatsu, antes de la II gran guerra, y luego, después de la segunda guerra mundial, con los keiretsu. Dichos bancos estaban restringidos a las orientaciones de la administración de estos grupos empresariales en sus decisiones sobre asignación del crédito (Collantes, 2008; Ohno, 2006).

El éxito de este singular modelo de capitalismo era claro en los primeros años de la década de 1970, momento en el que Japón ya había realizado logrado la convergencia económica con respecto a los países desarrollados occidentales y era una de las grandes economías del mundo. A pesar del explícito contexto internacional favorable se afirma que muchas otras economías atrasadas no habían con- seguido grado similar de desarrollo económico. Al parecer la diferencia entre Japón y estas economías atrasadas está en factores económicos y sociales de carácter endógeno (Collantes, 2008; Nishijima, 2009). Por tanto, parece claro que el modelo japonés, con sus grandes grupos empresariales, su paternalismo laboral, su dualismo estructural, su Estado activo, había tenido éxito.

\section{A modo de conclusión}

En primer lugar, se establece que para entender la evolución de la economía japonesa en el siglo XX es necesario conocer cómo transcurrió el Japón en los tres siglos anteriores, pues durante esa gran fase ocurrieron profundos cambios políticos, económicos y sociales, tanto en el pensamiento como en su comportamiento social y sus instituciones políticas. En este sentido, se argumenta que las condiciones necesarias para el gran crecimiento económico de Japón en el periodo 1945-1973, y su posterior desarrollo, están soportadas, en principio, en las reformas políticas, económicas y sociales que llevaron a cabo los gobiernos samurai y que fueron mejoradas y profundizadas durante la era Meiji.

En segundo lugar, se destaca el papel activo del Estado aun desde el periodo Edo donde el gobierno impulso un cambio radical en el esquema educativo en el país, y luego durante la era Meiji cuando el gobierno estableció la formación técnica y superior en la educación y desarrolló programas de formación de ciudadanos japoneses en las universidades de Estados unidos, Inglaterra y Alemania. De igual forma, se destaca el impulso del Estado al fortalecimiento de la industria japonesa a través de la transferencia de tecnología, el crédito blando y la protección comercial en materia de intercambio con respecto a los países de occidente.

Por otra parte, también se destaca a la triada gobierno, grupos empresariales y bancos como un elemento clave en el logro del crecimiento económico japonés durante periodo analizado. Esta unión, desde principios del siglo XX, permitió un esquema más flexible de la gestión empresarial, mayor financiamiento de recursos de capital para la inversión a bajos costos y un mayor poder de mercado durante 
un periodo de tiempo amplio para aprovechar las economías de escala y los subsecuentes rendimientos crecientes de la producción, que a su vez potenciaron el desarrollo tecnológico, las mayores exportaciones con alto valor agregado y un gran tamaño del mercado interno lo cual condujo a un incremento acelerado de riqueza per cápita y, en consecuencia, a un avance en el desarrollo económico no visto en ningún país durante el periodo 1970-1990, época en que Japón cayó en un estancamiento del crecimiento económico, del cual aún no sale.

Para finalizar, se plantea que el entorno mundial que se da entre 1945 y 1970, le da un impulso a la economía japonesa sin precedentes en país alguno en el mundo lo cual, unido a los factores endógenos madurados a lo largo de más de trescientos años, lograron llevar a la economía del Japón a la cumbre, en lo que en la literatura se ha conocido como el milagro económico japonés.

\section{Referencias}

Briceño, A. (2013). Desarrollo en Japón: Revolución Meiji y Postguerra, enseñanzas para Colombia, Tesis de grado de economía, Universidad Nacional de Colombia, Facultad de Ciencias Económicas.

Collantes, F. (2008). El milagro japonés y el desarrollo del Lejano Oriente, recuperado de http://www.unizar.es/departamen- tos/estructura_economica/personal/collantf/documents/ Japon-Texto.pdf

Miyamoto, M. et al. (1995). Nihon Keieishi: Nihon-gata Kigyo Keiei no Hatten, Edo kara Heisei e (History of Japanese Management: Development of the Japanese Management Model from Edo to Heisei), Yuhikaku.

Mosk, C. (2007). Japanese economic development: markets, norms, structures. Abingdon, Routledge.

Nishijima, S. (2009). Desarrollo económico de Japón y política industrial de Japón: implicaciones para países en desarrollo, RIBE Discussion Paper Series No. 246, Instituto de Investigación para Economía y Administración (RIEB).

Ohno, K. (2006). The Economic Development of Japan: The Path Traveled by Japan as a Developing Country, GRIPS Development Forum, National Graduate Institute for Policy Studies.

Okazaki, T. (1999). Edo no Sijo Keizai: Rekishiseido Bunseki kara Mita Kabunakama (The Market Economy of Edo: Trade Cartels from the Viewpoint of Historical Institutional Analysis), Kodansha Sensho Metier.

Tanaka, K. (2000). Hyakusho no Edo Jidai (The Edo Period Led by Farmers), Chikuma Shinsho.

Tello, C. (1964). El desarrollo económico de Japón, Foro Internacional, 4 (16), 552-570.

Teranishi, J. \& Kosai, Y. (1993). The Japanese Experience of Economic Reforms, Londres, St. Martin's Press.

Yoshikawa, H. (1997). Kodo Seicho: Nihon o Kaeta 6000 Nichi (The High- Growth Period: 6000 Days That Changed Japan), Yomiuri Shimbunsha.

Zalduendo, E. (1995). El desarrollo económico de Japón, Boletín de Lecturas Sociales y Económicas, 2(7), 17-28. 